\title{
Biomechanical evaluation of a biomimetic spinal construct
}

Tian Wang ${ }^{1,2}$, Jonathon R Ball ${ }^{3}$, Mattew H Pelletier ${ }^{1}$ and William R Walsh ${ }^{1 *}$

\begin{abstract}
Background: Laboratory spinal biomechanical tests using human cadaveric or animal spines have limitations in terms of disease transmission, high sample variability, decay and fatigue during extended testing protocols. Therefore, a synthetic biomimetic spine model may be an acceptable substitute. The goal of current study is to evaluate the properties of a synthetic biomimetic spine model; also to assess the mechanical performance of lateral plating following lateral interbody fusion.

Methods: Three L3/4 synthetic spinal motion segments were examined using a validated pure moment testing system. Moments $( \pm 7.5 \mathrm{Nm}$ ) were applied in flexion-extension (FE), lateral bending (LB) and axial rotation (AR) at $1 \mathrm{~Hz}$ for total 10000 cycles in MTS Bionix. An additional test was performed 12 hours after 10000 cycles. $\mathrm{A} \pm 10 \mathrm{Nm}$ cycle was also performed to allow provide comparison to the literature. For implantation evaluation, each model was tested in the 4 following conditions: 1) intact, 2) lateral cage alone, 3) lateral cage and plate 4) anterior cage and plate. Results were analysed using ANOVA with post-hoc Tukey's HSD test.
\end{abstract}

Results: Range of motion (ROM) exhibited logarithmic growth with cycle number (increases of $16 \%, 37.5 \%$ and $24.3 \%$ in AR, FE and LB respectively). No signification difference ( $p>0.1)$ was detected between 4 cycles, 10000 cycles and 12 hour rest stages. All measured parameters were comparable to that of reported cadaveric values. The ROM for a lateral cage and plate construct was not significantly different to the anterior lumbar interbody construct for FE $(p=1.00), L B(p=0.995)$ and AR $(p=0.837)$.

Conclusions: Based on anatomical and biomechanical similarities, the synthetic spine tested here provides a reasonable model to represent the human lumbar spine. Repeated testing did not dramatically alter biomechanics which may allow non-destructive testing between many different procedures and devices without the worry of carry over effects. Small intra-specimen variability and lack of biohazard makes this an attractive alternative for in vitro spine biomechanical testing. It also proved an acceptable surrogate for biomechanical testing, confirming that a lateral lumbar interbody cage and plate construct reduces ROM to a similar degree as anterior lumbar interbody cage and plate constructs.

Keywords: Synthetic; Lumbar; Sowbones; Biomechanical; Interbody cage; Lateral plate; Anterior plate; Pure moment; Sawbones; Motion segment; Fatigue

\footnotetext{
* Correspondence: wrwalshau@gmail.com

'Surgical \& Orthopaedic Research Laboratories, Prince of Wales Clinical

School, University of New South Wales, Clinical Science Bldg, Prince of Wales

Hospital, Gate 6, Avoca Street, 2031 Sydney, Australia

Full list of author information is available at the end of the article
}

\section{空

(C) 2014 Wang et al.; licensee Springer. This is an Open Access article distributed under the terms of the Creative Commons Attribution License (http://creativecommons.org/licenses/by/4.0), which permits unrestricted use, distribution, and reproduction in any medium, provided the original work is properly credited. 


\section{Background}

Development of synthetic replicates has been driven by the challenges associated with using fresh tissues for biomechanical testing. Beyond scarcity and cost considerations, fresh samples are biohazards and require appropriate personal protective equipment as well as the enactment of handling and specimen tracking procedures. There are also social and ethical concerns that must be addressed. Additional limitations that are particularly relevant to the spine include fluctuations in soft and hard tissues properties over time and with exposure to air, which alters the kinematic response of motion segments [1]. During high cycle fatigue tests spinal segments are likely to suffer from tissue putrefaction. Freezing tissues offers an means to hinder decomposition, however initial freezing itself will also influence mechanical properties [2]. With the amount of time between expiration of the donor and subsequent freezing uncontrolled variables, this is likely to further influence the condition of the tissues. Initial tissue quality is also an issue as the majority of the cadaveric specimen is from elderly donors with osteoporosis, or other degenerative pathologies. Inherent inter-specimen variability in size, bone quality and disc pressure [3] will increase data scatter. Animals are a suitable replacement for human cadaveric spines in certain testing protocols [4-11] with well reported anatomical and biomechanical comparisons [12,13] but have limitation in terms of size and angle of lordosis. While these samples may be more easily accessible and more cost effective, they still embody the previously mentioned limitations with human tissues.

The creation of a biomechanically accurate joint complex including soft tissues presents a challenge beyond that of modeling individual bones [14-18]. Further complicating this process in the spine is that intervertebral joints consist two articulating synovial joints (zygapophyseal joints) and one symphysis (intervertebral disc), as well as surrounding syndesmoses (anterior and posterior longitudinal, inter- and supraspinous, intertransverse ligaments and ligamentaflava).

A novel synthetic spinal testing models recently released by Sawbones may have utility in research and development. The current study examined the anatomy and biomechanical aspects of this synthetic biomimetic spine model in cyclic testing; and to evaluate anterior and lateral plating with interbody cages, to address the following questions: 1) is a lateral interbody cage + plate construct mechanically comparable to an anterior interbody cage + plate construct; and 2) is a stand-alone lateral interbody cage construct mechanically comparable to the intact state.

\section{Methods}

\section{Evaluation of anatomy}

Three L3/4 synthetic spinal motion segments, recently developed by SawBones (Vashon, WA, USA) were evaluated.
Samples were examined using clinical computed tomography (CT Aquilion PRIME; Toshiba, Tokyo, Japan) with $0.5 \mathrm{~mm}$ slices. 3D models, which were built with Mimics (Materialise, Leuven, Belgium) from the DICOM data, were used to measured anatomy parameters such as end plate depth, end plate width, vertebral body height, spinal canal depth, spinal canal width, pedicle height and pedicle width. Results were compared with anatomical data from the human [19] and sheep [12] lumbar spine.

\section{Cyclic tests}

Motion segments were examined with a validated pure moment testing system $[20,21]$. Moments $( \pm 7.5 \mathrm{Nm})$ were applied in flexion-extension (FE), lateral bending (LB) and axial rotation (AR) at $1 \mathrm{~Hz}$ for total 10000 cycles in MTS Bionix (MTS Systems, Eden Prairie, MN) with $25 \mathrm{KN}$ axial-torsional load transducer (model number: 662.20D05, MTS system corporation, Eden Prairie, MN, USA). Motion was assessed at 4, 125, 250, 500, 1000, 2500, 5000 and 10000 cycles. A non-contacting thermometer was used to measure the temperature of disc, endplate and vertebral body at each assessment stage. After a 12 hour rest period, an additional test was run at $\pm 7.5 \mathrm{Nm}$ to determine the influence of temperature (designed as recovery group test). A $\pm 10 \mathrm{Nm}$ cycle was performed to allow additional comparison to the literature, and act as the intact group (INT) for subsequent instrumented tests. A near infrared 3D motion tracking system with retroreflective markers (Osprey, Motion Analysis, Santa Rosa, CA) was employed to record the motion of the sample. Pretesting calibration found the system accuracy within $0.1 \mathrm{~mm}$ in displacement and $0.1^{\circ}$ in rotation. Post processing was performed with an in-house written script MATLAB (MathWorks, Natick, MA) to extract the torque-angle curves and resulting range of motion (ROM) and neutral zone (NZ). NZ was calculated based on the Wilke et al. [22].

\section{Implanted conditions}

Four cycles $( \pm 10 \mathrm{Nm})$ were applied in the primary anatomical planes. The intact group (INT) results were obtained during the cycle test mentioned above. Each sample was tested in three additional states (Figure 1), 1) lateral interbody cage alone (LIC); 2) lateral interbody cage + plate (LICP); and 3) anterior interbody cage + plate (AICP). PEEK interbody cages (K2M Aleutian, Life Health Care, North Ryde, Australia) were used in this study. The rigid plating system used consisted of a locking plate and four cancellous screws (K2M Cayman, LifeHealthCare, North Ryde, Australia). The implants were sized appropriate to specimen anatomy. Firstly, a box-like incision was made through the lateral annulus followed by discectomy. The disc material was removed using a surgical curette and rongeur. The anterior longitudinal ligament and part 


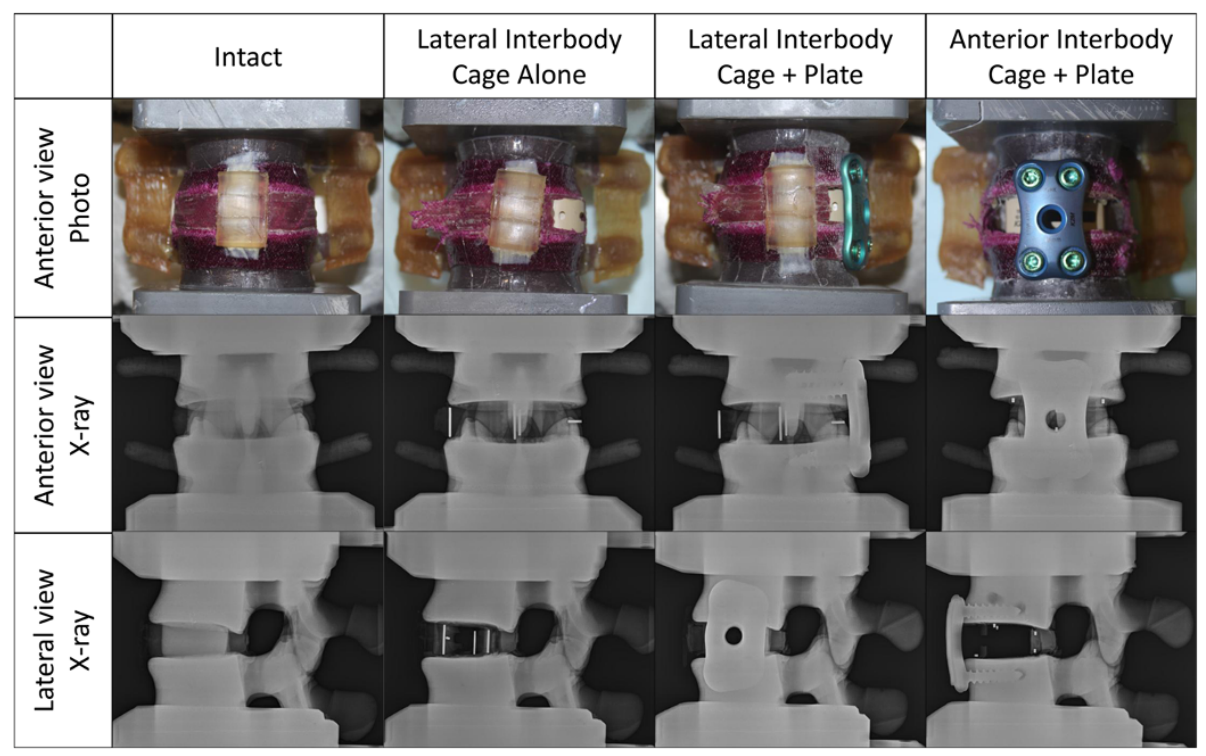

Figure 1 Anterior view photo, anterior view x-ray and lateral view x-ray imaging of different sample conditions.

of anterior annulus was still connected at this stage. The lateral cage $\left(14 \mathrm{~mm} \times 8^{\circ}\right)$ was implanted, and mechanically tested (LIC). A43 mm lateral locking plate was secured with four $6.0 / 28 \mathrm{~mm}$ cancellous screws and mechanically tested (LICP). The lateral interbody cage and plate was removed, the anterior longitudinal ligament and annulus were cut through and a complete discectomy performed. The anterior interbody cage $\left(15 \mathrm{~mm} \times 10^{\circ}\right)$ and plate (38 mm with $6.0 / 28 \mathrm{~mm}$ screws) were then applied and the sample tested (ALCP). Radiographs were taken before and after testing with a high resolution X-ray (MX-20; Faxitron, Tucson, AZ).

\section{Statistical analysis}

Data from cyclic tests was analyzed using one way ANOVA with a 0.05 significance level with IBM SPSS Statistics (version 21, IBM, Armonk, NY), followed by a Tukey HSD post hoc analysis. For implanted conditions, ANOVA was again applied followed by Tukey HSD post hoc analysis between test conditions.

\section{Results}

\section{Anatomy}

L3 and L4 anatomical parameters of the synthetic spine model are compared with published human [19] and sheep [12] L3 and L4 data in Table 1. The synthetic model anatomy showed a close match to the human, while the sheep differs to the other two groups, as expected.

\section{Cyclic tests}

Figure 2 shows the individual sample FE, LB and AR ROM results against cycle number. After $10 \mathrm{~K}$ cycles, the average ROM of three samples increased 16\%, 37.5\% and $24.3 \%$ in AR, FE and LB respectively. All samples displayed logarithmic growth in ROM with increasing cycle number. However, it was also noted that the absolute value of the ROM differed for samplelagainst other two, particularly in LB. The mean value for ROM increased from 4 to $10 \mathrm{~K}$ cycles and decreased slightly following the recovery period (Figure 3); however no signification differences $(p>0.1)$ were detected between any of these groups. When compared with the $10 \mathrm{Nm}$ cadaveric test results of Panjabi et al. [23] and [24] (Table 2), synthetic ROM were similar to the human data. And for NZ results, most FE NZ and LB NZ were in the range of the cadaveric data, but the AR NZ was smaller than reported human results. Furthermore, compared with human data, the synthetic spine reduced standard deviation by $10 \%, 30 \%$ and $57.5 \%$ in $\mathrm{AR}, \mathrm{FE}$, and LB ROM respectively.

\section{Implanted conditions}

As expected, the ROM of the lateral cage alone group was less than the intact group, and was further reduced with the plate fixation (Figure 4). Quantitative results shown that the ROM of flexion/extension decreased by $51.5 \%$ with a lateral cage alone. Further decrease was obtained with a lateral cage + lateral plate (77.8\%); this magnitude of reduction was similar to that seen with an anterior cage + plate $(81.7 \%)$. ROM in lateral bending decreased by $68.2 \%$ with a lateral cage alone and further decreased with a lateral cage + plate (87.9\%). This magnitude of reduction was greater than that seen with an anterior cage + plate $(74.7 \%)$. Axial rotation ROM decreased minimally with a lateral cage alone (18.9\%), and to a greater 
Table 1 Anatomical comparison between synthetic model, human cadaver and sheep; (I) indicates inferior or caudal level; number in brackets indicated the standard deviation

\begin{tabular}{|c|c|c|c|c|c|c|}
\hline & \multicolumn{3}{|c|}{ L3 } & \multicolumn{3}{|c|}{ L4 } \\
\hline & Synthetic model & Human & Sheep & Synthetic model & Human & Sheep \\
\hline End plate depth(I) & $35.48(0.46)$ & $34.80(1.24)$ & $20.00(0.60)$ & $37.09(1.05)$ & $33.90(0.85)$ & $20.10(0.70)$ \\
\hline End plate width(I) & $49.85(0.76)$ & $48.00(1.24)$ & $29.80(1.30)$ & $52.36(0.61)$ & $49.50(1.38)$ & $31.00(0.60)$ \\
\hline Vertebral body height & $26.76(0.03)$ & $23.80(1.10)$ & $40.20(1.20)$ & $23.96(0.86)$ & $24.10(1.10)$ & $41.10(0.80)$ \\
\hline Spinal canal depth & $20.62(0.19)$ & $17.50(0.53)$ & $8.60(0.70)$ & $21.38(0.45)$ & $18.60(0.71)$ & $8.80(0.40)$ \\
\hline Spinal canal width & $23.53(0.80)$ & $24.30(0.64)$ & $12.60(1.10)$ & $23.37(1.05)$ & $25.40(0.49)$ & $12.90(1.10)$ \\
\hline Pedicle height & $13.93(0.90)$ & $14.40(0.62)$ & $35.70(1.40)$ & $16.49(0.44)$ & $15.40(0.46)$ & $36.30(1.40)$ \\
\hline Pedicle width & $12.88(0.85)$ & $10.20(0.60)$ & $9.50(0.90)$ & $11.49(0.27)$ & $14.10(0.46)$ & $9.60(1.00)$ \\
\hline
\end{tabular}

extent with a lateral cage + plate $(65.6 \%)$. This magnitude of reduction was similar to that seen with an anterior cage + plate (66.3\%). In addition, cadaveric studies which investigate ROM of lateral interbody cage fusion with and without plate fixation [25-28] (Table 3) correlate well with the current study. Statistical analyses revealed differences between the intact and two cage + plate groups $(\mathrm{p}<0.05$ in $\mathrm{AR}$ and $\mathrm{p}<0.01$ in FE and LB). No statistic differences were detected between lateral cage + plate and arterial cage + plate; or between intact and lateral cage alone groups, except in LB $(\mathrm{p}<0.01)$.

\section{Discussion}

The present study evaluated the response of the novel synthetic spine models to pure moment loading in all three anatomical planes under high cycle testing as well as following implantation with interbody cages and anterior/lateral plates. The anatomy of the synthetic spine compared to published data [12,19] was also reported. Results showed this synthetic spine model presents a better simulation in terms of anatomy than other spine surrogates for the human spine [29-36] (Table 1). The intact synthetic model has comparable biomechanics compared to published results for intact human cadaveric spine segments [23,24] (Table 2). A key measure of spinal kinematics is ROM. When comparing with human spines, ROM results were within the range of the human data, except AR ROM for sample1. NZ represents the lax portion of bending where relatively small loads cause large rotations [23]. Overall, NZ for FE and LB were within the

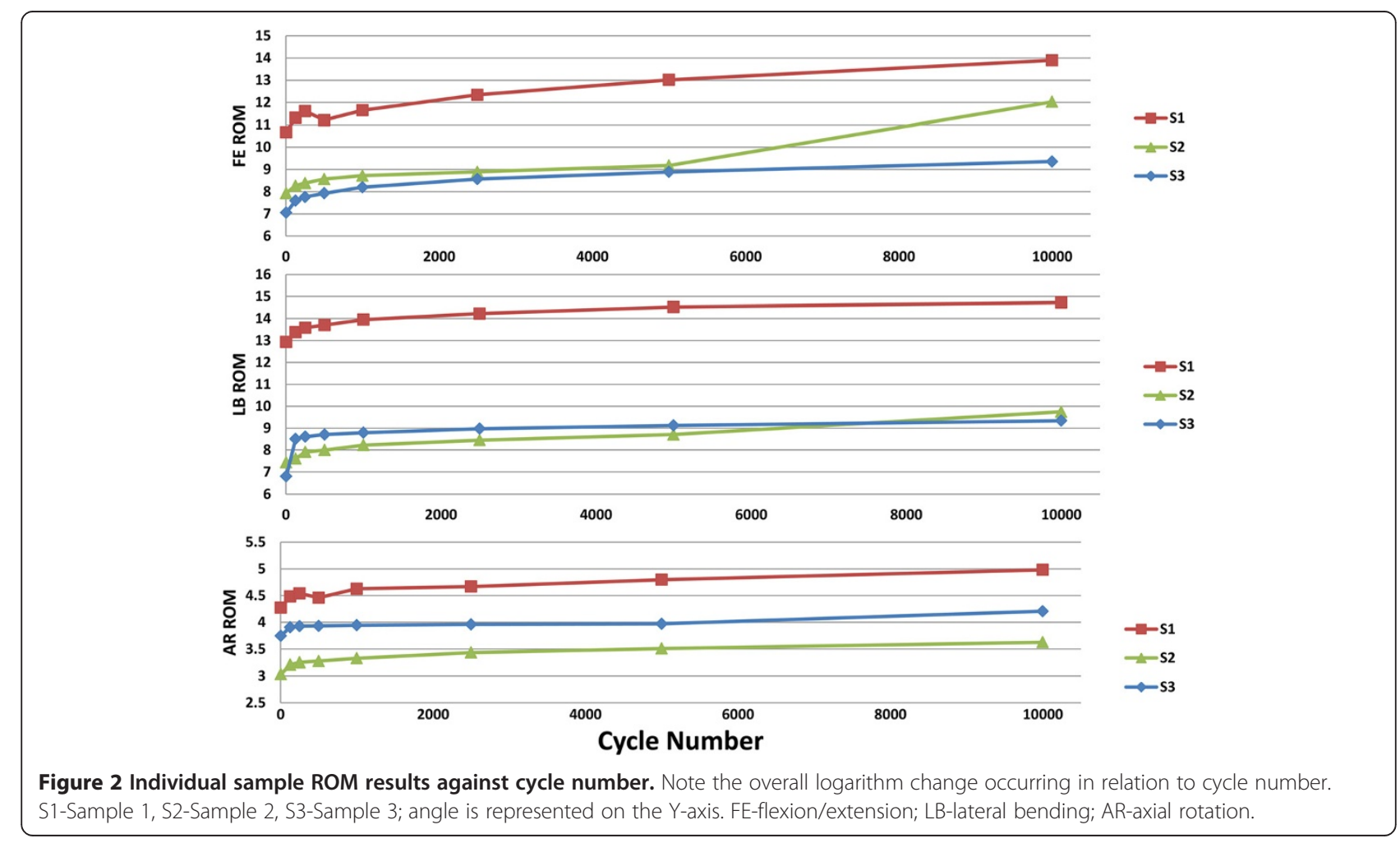




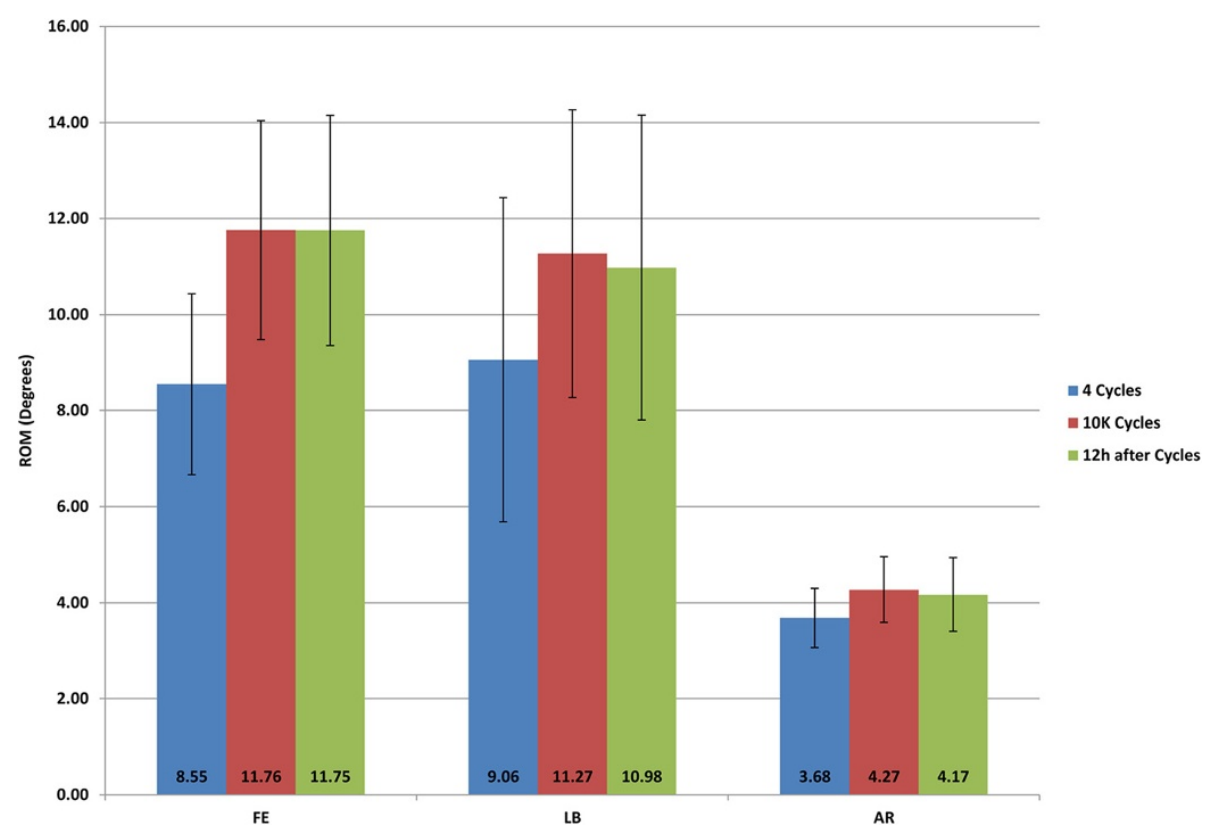

Figure 3 ROM comparison between 4 cycles, $10 \mathrm{~K}$ cycles and recovery. FE-flexion/extension; LB-lateral bending; AR-axial rotation.

human data range. In addition, the smaller standard deviation in ROM for all modes of bending, when compared with human data, would be expected to increase repeatability when used for this type of scientific research.

The 10,000 cycle test sequence results represented a long test life of this synthetic model. Although this would not be expected to represent true fatigue testing of implanted constructs in a spine, it is likely to span the working life of the spine in a laboratory environment. Results showed that ROM logarithmically increased with cycle number (Figure 2). Although after $10 \mathrm{~K}$ cycles ROM in all three motions had different magnitudes of increase, the final round of tests showed that the ROM was still within range of human.

The decrease in stiffness is likely due to two primary reasons: material property changes and mechanical bonding failure brought by fatigue. Material properties may change permanently due to microscopic failure points induced by cyclic loading, or transiently due to local temperature change. Traditional measures of spinal biomechanics present a torque/angle plot containing a

Table $210 \mathrm{Nm}$ ROM and NZ results comparing with human cadaveric data

\begin{tabular}{cccccccccc}
\hline & \multicolumn{4}{c}{ ROM (degree) } & & \multicolumn{3}{c}{ NZ (degree) } \\
\cline { 2 - 4 } \cline { 8 - 10 } & s1 & s2 & s3 & White [24] & & s1 & s2 & s3 & Panjabi [23] \\
\hline FE & 22.9 & 15.7 & 12.8 & $15.0(7.0)$ & & 0.8 & 0.9 & 0.9 & $0.7(0.6)$ \\
LB & 18.4 & 12.7 & 11.7 & $16.0(8.0)$ & & 2.3 & 1.1 & 1.0 & $0.9(0.8)$ \\
AR & 8.0 & 5.1 & 4.8 & $5.2(2.0)$ & & 0.8 & 0.8 & 0.7 & $1.3(0.4)$ \\
\hline
\end{tabular}

S1-Sample 1, S2-Sample 2, S3-Sample, number in brackets indicated the standard deviation. hysteresis curve. This hysteresis area represents the amount of energy that is lost during the cycle. This energy is expended by causing permanent damage or is lost as heat. In the present test, a non-contacting thermometer showed that after $10 \mathrm{~K}$ cycles, local temperature increased up to $5^{\circ} \mathrm{C}$ in FE and LB motions at the intersection between disc and vertebral body. An additional source of heat may have been friction between the different material components. However, the ROM did not change significantly following cooling and recovery over 12 hours (Figure 3). This suggests that the temperature increase may not be the primary driver for changing mechanical properties. Visual inspection found that there were fibers broken in the outer annulus fibrosis, particularly at the intersection between disc and vertebral body. This area represents an abrupt change in material properties which the simulated outer annulus helped to transition. Failure of this construct is likely to have been responsible for a fair portion of the changing biomechanics.

Repeated testing with differing implanted conditions showed the influence of interbody cage placement and plating on spinal biomechanics (Figure 4). Compared with the intact state, lateral interbody cage placement did not affect $\mathrm{AR}$, trending towards a significant reduction in FE $(\mathrm{p}=0.06)$, and significantly reduced in LB. The geometry and size of the lateral cage provides support in LB via a large footprint and extended lateral dimension, which likely contributed to these findings.

Differences in testing methodology make it difficult to draw exact comparisons with other cadaveric biomechanical 
Table 3 Comparison of the current study results with relevant studies

\begin{tabular}{|c|c|c|c|c|c|}
\hline Author/Publication & Applied torque $[\mathrm{N} \cdot \mathrm{m}]$ & Test conditions & FE ROM [\% Intact] & LB ROM [\% Intact] & AR ROM [\% Intact] \\
\hline \multirow[t]{2}{*}{ Current study } & \pm 10 & Lateral cage alone & $48.5 \%$ & $31.4 \%$ & $81.3 \%$ \\
\hline & & Lateral cage and plate & $22.2 \%$ & $11.9 \%$ & $33.9 \%$ \\
\hline \multirow[t]{2}{*}{ Cappuccino et al., 2010 [26] } & \pm 7.5 & XLIF cage alone & $31.6 \%$ & $32.5 \%$ & $69.4 \%$ \\
\hline & & XLIF + lateral plate & $32.5 \%$ & $15.9 \%$ & $53.4 \%$ \\
\hline \multirow[t]{2}{*}{ Bess et al., 2008 [25] } & \pm 5 & XLIF cage alone & $45.8 \%$ & $41.8 \%$ & $66.3 \%$ \\
\hline & & XLIF + lateral plate & $40.0 \%$ & $24.2 \%$ & $50.7 \%$ \\
\hline \multirow[t]{2}{*}{ Le Huec et al., 2002 [28] } & \pm 7 & LLIF cage alone & $71.3 \%$ & $88.5 \%$ & $107.7 \%$ \\
\hline & & LLIF cage + lateral plate & $40.3 \%$ & $27.3 \%$ & $45.2 \%$ \\
\hline \multirow[t]{2}{*}{ Kim et al., 2005 [27] } & \pm 7.5 & LLIF graft alone & $75.2 \%$ & $96.9 \%$ & $71.6 \%$ \\
\hline & & LLIF + lateral plate & $52.1 \%$ & $37.9 \%$ & $41.3 \%$ \\
\hline
\end{tabular}

XLIF-eXtreme Lateral Interbody Fusion; LLIF - Lateral Lumbar Interbody Fusion.

studies. However, similar trends in outcomes can be identified [25] and [26] used a human cadaver model to compare lumbar spine kinematics of a laterally placed interbody device used as a stand-alone construct with various instrumented constructs (Table 3). They tested 5 conditions: (1) intact spine, (2) lateral discectomy and stand-alone lateral interbody device (XLIF), (3) XLIF supplemented by a lateral plate, (4) XLIF supplemented by unilateral pedicle screws, and (5) XLIF supplemented by bilateral pedicle screws. Results revealed that the extreme lateral interbody implant, with or without supplemental fixation, provides primary stabilization in all loading modes compared with intact specimens. The greatest reduction in ROM was observed with lateral bending and flexion-extension in all treatments. Le Huec et al. [28] compared the biomechanics of lateral interbody cage in 8 cadaveric lumbar functional spinal units with 2 additional modes of fixation: a lateral plate and a lateral plate locked to the cage. The laterally placed cage produced a decrease in the ROM compared with intact in flexion extension and lateral bending, but not in axial rotation. The reduction in ROM observed with the plate was significantly reduced relative to the intact spine in all 3 motion planes. Kim et al. [27] evaluated the stability of human cadaveric lumbar spine constructs with interbody reconstruction performed via a traditional ALIF approach or a lateral approach. Specimens

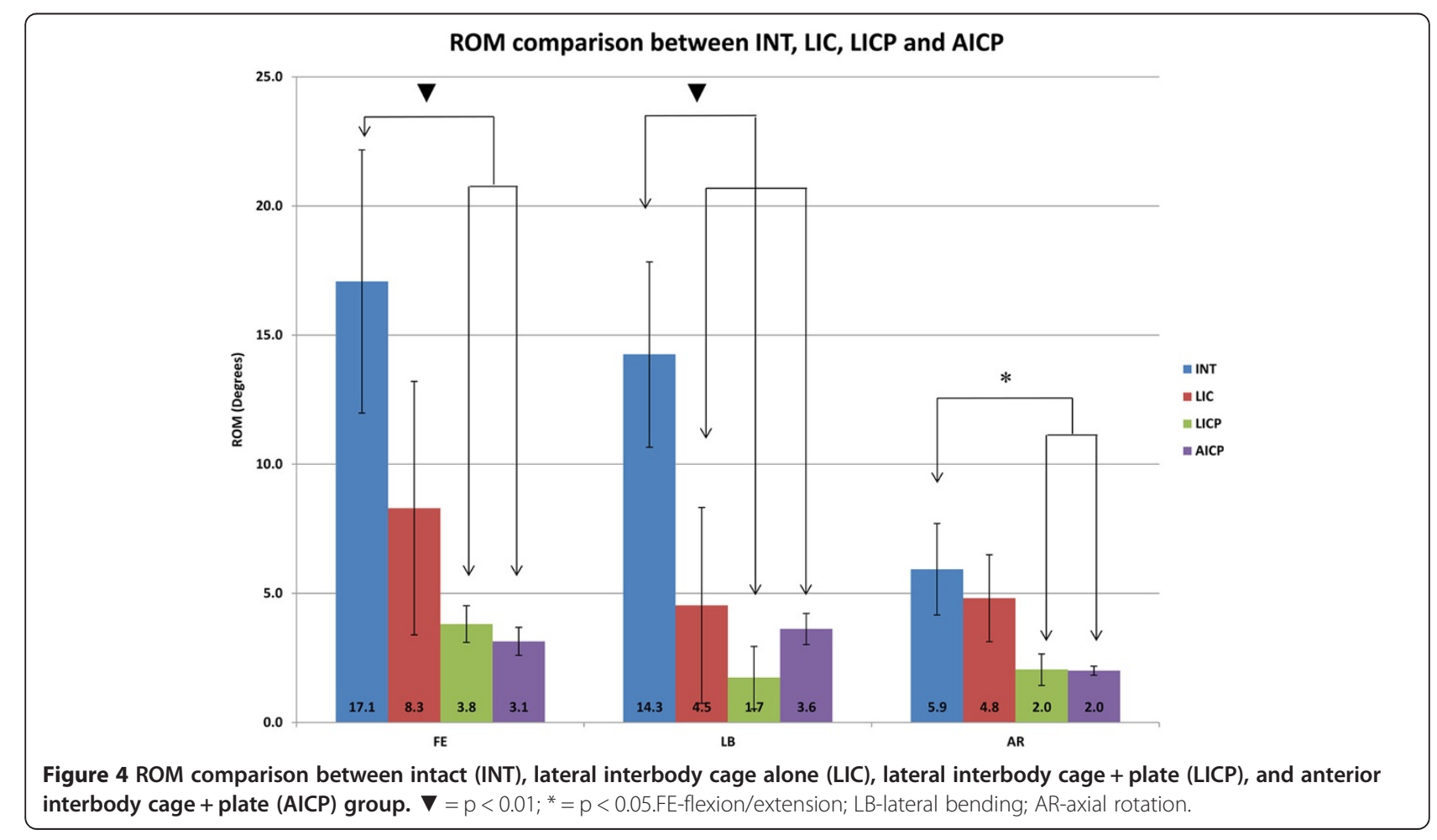


were evaluated in 4 conditions: (1) intact spine, (2) destabilization by anterior or lateral discectomy, (3) stand-alone interbody reconstruction and (4) interbody reconstruction supplemented with additional fixation. The stand-alone lateral interbody and ALIF implants restored the ROM and $\mathrm{NZ}$ to intact spine values. Compared with the intact spine, supplemental instrumentation significantly reduced the ROM and NZ in all loading modes.

In summary, these cadaveric tests results indicated three primary points. Firstly, the stand-alone lateral interbody cage provided primary stabilization, which is supported by the present study. The present study showed that lateral interbody cage alone can reduce the ROM $48.5 \%$ and $31.4 \%$ in flexion-extension and lateral bending respectively. Similar reduction can be found in published literature (Table 3). Second, a stand-alone cage did not provide sufficient axial rotational stabilization (66.3\%-107.7\%), and this was confirmed again by the present study (81.3\%). Third, a supplementary lateral plate with screws significantly reinforces the stabilization in all directions. Again, this is supported by the current study. However, a larger reduction in ROM has been found in current study compared to cadaveric data $(22.2 \%, 11.9 \%$ and $33.9 \%$ in $\mathrm{FE}$, LB and AR respectively vs. $32.5-52.1 \%, 15.9-37.9 \%$, and 41.3-53.4\% with cadaveric sample). This might due to the different loads applied. It also should be noted that the vertebral bodies do not contain simulated cancellous bone. The solid nature of the vertebrae may overestimate the fixation achievable by screws and limit the amount of deformation at the disc/endplate interface.

\section{Limitations}

The primary limitation of this study is the small sample size which did not allow robust statistical analysis. Additionally no cadaveric samples were tested for direct comparison. To allow comparison with cadaveric values published results were utilized. This provided mean values but did not allow for any statistical analysis. The destructive nature of the implanted conditions dictated that each sample follow a standard order. Randomized tests with individual samples for each intact and implanted condition may be desirable for future testing.

\section{Conclusion}

This study found that based on the anatomy and biomechanical similarities, the synthetic spine tested here provides a reasonable model to represent the human lumbar spine. Repeated testing did not dramatically alter biomechanics which may allow non-destructive testing between many different procedures and devices without the worry of carry over effects. Small intra-specimen variability and lack of biohazard makes this an attractive alternative for in vitro spine biomechanical testing. However, a preconditioning test should be run to check the initial ROM of each sample. It also proved an acceptable surrogate for biomechanical testing, confirming that a lateral lumbar interbody cage and plate construct reduces ROM to a similar degree as anterior lumbar interbody cage and plate constructs. Clearly, more testing is required in the future to evaluate this synthetic model for more complex applications.

\section{Abbreviations}

ROM: Range of motion; NZ: Neutral zone; FE: Flexion-extension; LB: Lateral bending; AR: Axial rotation; INT: Intact group; LIC: Lateral interbody cage alone; LICP: Lateral interbody cage with plate; AICP: anterior interbody cage with plate; XLIF: Lateral discectomy and stand-alone lateral interbody device; LLIF: Lateral lumbar interbody fusion; ALIF: Anterior lumbar interbody fusion.

\section{Competing interests}

The authors declare that they have no competing interests.

\section{Authors' contributions}

TW and MP carried out the mechanical test, performed the statistical analysis and drafted the manuscript. JB participated in the implantation test, also data analysis. WW conceived of the study, and participated in its design and coordination and helped to draft the manuscript. All authors read and approved the final manuscript.

\section{Author details}

'Surgical \& Orthopaedic Research Laboratories, Prince of Wales Clinical School, University of New South Wales, Clinical Science Bldg, Prince of Wales Hospital, Gate 6, Avoca Street, 2031 Sydney, Australia. ${ }^{2}$ Graduate School of Biomedical Engineering, University of New South Wales, Sydney, NSW, Australia. ${ }^{3}$ Royal North Shore Hospital, St Leonards, NSW, Australia.

Received: 24 February 2014 Accepted: 8 May 2014

Published: 26 June 2014

\section{References}

1. Wilke H-J, Jungkunz B, Wenger K, Claes LE (1998) Spinal segment range of motion as a function of in vitro test conditions: Effects of exposure period, accumulated cycles, angular-deformation rate, and moisture condition. Anat Rec 251(1):15-19. doi:10.1002/(SICI)1097-0185(199805)251:1<15::AID-AR4>3.0. CO;2-D

2. Hongo M, Gay RE, Hsu J-T, Zhao KD, Ilharreborde B, Berglund LJ, An K-N (2008) Effect of multiple freeze-thaw cycles on intervertebral dynamic motion characteristics in the porcine lumbar spine. J Biomech 41(4):916-920. doi:10.1016/j.jbiomech.2007.11.003

3. Cunningham BW, Kotani Y, McNulty PS, Cappuccino A, McAfee PC (1997) The effect of spinal destabilization and instrumentation on lumbar intradiscal pressure: an in vitro biomechanical analysis. Spine 22(22):2655-2663

4. Shono Y, Kaneda K, Abumi K, McAfee PC, Cunningham BW (1998) Stability of posterior spinal instrumentation and its effects on adjacent motion segments in the lumbosacral spine. Spine (Phila Pa 1976) 23(14):1550-1558

5. Kotani Y, Cunningham BW, Abumi K, McAfee PC (1994) Biomechanical analysis of cervical stabilization systems: an assessment of transpedicular screw fixation in the cervical spine. Spine 19(22):2529-2539

6. Bozkus H, Chamberlain RH, Perez Garza LE, Crawford NR, Dickman CA (2004) Biomechanical comparison of anterolateral plate, lateral plate, and pedicle screws-rods for enhancing anterolateral lumbar interbody cage stabilization. Spine (Phila Pa 1976) 29(6):635-641

7. Grubb MR, Currier BL, Shih J-S, Bonin V, Grabowski JJ, Chao EY (1998) Biomechanical evaluation of anterior cervical spine stabilization. Spine 23(8):886-892

8. Richman JD, Daniel TE, Anderson DD, Miller PL, Douglas RA (1995) Biomechanical evaluation of cervical spine stabilization methods using a porcine model. Spine 20(20):2192

9. Schmidt R, Richter M, Claes L, Puhl W, Wilke H-J (2005) Limitations of the cervical porcine spine in evaluating spinal implants in comparison with human cervical spinal segments: a biomechanical in vitro comparison of 
porcine and human cervical spine specimens with different instrumentation techniques. Spine 30(11):1275-1282

10. Kanayama MMD, Cunningham BWMS, Weis JCMD, Parker LMMD, Kaneda KMD, McAfee PCMD (1998) The effects of rigid spinal instrumentation and solid bony fusion on spinal kinematics: a posterolateral spinal arthrodesis model. Spine 23(7):767-773

11. Sandén B, Olerud C, Johansson C, Larsson S (2001) Improved bone-screw interface with hydroxyapatite coating: an in vivo study of loaded pedicle screws in sheep. Spine 26(24):2673-2678

12. Wilke HJ, Kettler A, Wenger KH, Claes LE (1997d) Anatomy of the sheep spine and its comparison to the human spine. Anat Rec 247(4):542-555. doi:10.1002/(SICl)1097-0185(199704)247:4<542

13. Wilke HJ, Kettler A, Claes LE (1997) Are sheep spines a valid biomechanical model for human spines? Spine (Phila Pa 1976) 22(20):2365-2374

14. Bertollo N, Gothelf T, Walsh W (2008) 3-Fluted orthopaedic drills exhibit superior bending stiffness to their 2-fluted rivals: Clinical implications for targeting ability and the incidence of drill-bit failure. Injury 39(7):734-741

15. Bertollo N, Gothelf T, Walsh W (2013) In vitro analysis of drill Bit designs: 2 vs 3 flutes. Bone \& Joint J Orthopaedic Proc Supple 95(SUPP 15):133-133

16. Bougherara H, Zdero R, Mahboob Z, Dubov A, Shah S, Schemitsch E (2010) The biomechanics of a validated finite element model of stress shielding in a novel hybrid total knee replacement. Proc Inst Mech Eng H J Eng Med 224(10):1209-1219

17. Burroughs BR, Hallstrom B, Golladay GJ, Hoeffel D, Harris WH (2005) Range of motion and stability in total hip arthroplasty with 28-, 32-, 38-, and 44-mm femoral head sizes: an in vitro study. J Arthroplasty 20(1):11-19

18. Harris ML, Morberg P, Bruce WJM, Walsh WR (1999) An improved method for measuring tibiofemoral contact areas in total knee arthroplasty: a comparison of K-scan sensor and Fuji film. J Biomech 32(9):951-958. doi:10.1016/S0021-9290(99)00072-X

19. Panjabi MM, GOEL V, OXLAND T, TAKATA K, DURANCEAU J, KRAG M, PRICE M (1992) Human lumbar vertebrae: quantitative three-dimensional anatomy. Spine 17(3):299

20. Pelletier M, Cordaro N, Lau A, Walsh WR (2012) PEEK versus Ti interbody fusion devices: resultant fusion, bone apposition, initial and 26 week biomechanics. J Spinal Disord Tech. doi:10.1097/BSD.0b013e31826851a4

21. Spenciner D, Greene D, Paiva J, Palumbo M, Crisco J (2006) The multidirectional bending properties of the human lumbar intervertebral disc. Spine J 6(3):248-257. doi:10.1016/j.spinee.2005.08.020

22. Wilke HJ, Wolf $S$, Claes LE, Arand M, Wiesend A (1995) Stability increase of the lumbar spine with different muscle groups. A biomechanical in vitro study. Spine 20(2):192-198

23. Panjabi M (2003) Clinical spinal instability and low back pain. J Electromyogr Kinesiol 13(4):371-379. doi:10.1016/s1050-6411(03)00044-0

24. White AA, Panjabi MM (1990) Clinical Biomechanics of the Spine, 2nd edition. Lippincott, Philadelphia

25. Bess R, Cornwall G, Vance R, Bachus K, Brodke D (2008) Biomechanics of Lateral Arthrodesis. In: Goodrich JA, Volcan IJ (ed) eXtreme Lateral Interbody Fusion (XLIF). Quality Medical Publishing, St Louis, MO, pp 31-40

26. Cappuccino A, Cornwall GB, Turner AW, Fogel GR, Duong HT, Kim KD, Brodke DS (2010) Biomechanical analysis and review of lateral lumbar fusion constructs. Spine (Phila Pa 1976) 35(26 Suppl):S361-S367. doi:10.1097/BRS.0b013e318202308b

27. Kim SM, Lim TJ, Paterno J, Park J, Kim DH (2005) Biomechanical comparison: stability of lateral-approach anterior lumbar interbody fusion and lateral fixation compared with anterior-approach anterior lumbar interbody fusion and posterior fixation in the lower lumbar spine. J Neurosurg Spine 2(1):62-68. doi:10.3171/spi.2005.2.1.0062

28. Le Huec JC, Liu M, Skalli W, Josse L (2002) Lumbar lateral interbody cage with plate augmentation: in vitro biomechanical analysis. Eur Spine J 11(2):130-136. doi:10.1007/s005860100316

29. Au AG, Aiyangar AK, Anderson PA, Ploeg HL (2011) Replicating interbody device subsidence with lumbar vertebraesurrogates. Proc Inst Mech Eng H 225(10):972-985

30. Dick JC, Zdeblick TA, Bartel BD, Kunz DN (1997) Mechanical evaluation of cross-link designs in rigid pedicle screw systems. Spine 22(4):370-375

31. Murakami HH, Kawahara NN, Tomita KK, Sakamoto JJ, Oda JJ (2002) Biomechanical evaluation of reconstructed lumbosacral spine after total sacrectomy. J Orthop Sci 7(6):658-664

32. Penzkofer R, Hofberger S, Spiegl U, Schilling C, Schultz R, Augat $P$, Gonschorek O (2011) Biomechanical comparison of the end plate design of three vertebral body replacement systems. Arch Orthop Trauma Surg 131(9):1253-1259. doi:10.1007/s00402-011-1284-7

33. Stanford RE, Loefler AH, Stanford PM, Walsh WR (2004) Multiaxial pedicle screw designs: static and dynamic mechanical testing. Spine 29(4):367-375

34. Tokuhashi $Y$, Matsuzaki H, Shirasaki Y, Tateishi T (2000) C1 - C2 intra-articular screw fixation for atlantoaxial posterior stabilization. Spine 25(3):337-341

35. Wilke H-J, Russo G, Schmitt H, Claes L (1997) A mechanical model of human spinal motion segments-Ein mechanisches modell für humane wirbelsäulenbewegungssegmente. Biomed Tech (Berl) 42(11):327-331

36. Yinger K, Scalise J, Olson SA, Bay BK, Finkemeier CG (2003) Biomechanical comparison of posterior pelvic ring fixation. J Orthop Trauma 17(7):481-487

doi:10.1186/s40634-014-0003-z

Cite this article as: Wang et al:: Biomechanical evaluation of a

biomimetic spinal construct. Journal of Experimental Orthopaedics 2014 1:3.

\section{Submit your manuscript to a SpringerOpen ${ }^{\odot}$ journal and benefit from:}

- Convenient online submission

$\checkmark$ Rigorous peer review

- Immediate publication on acceptance

- Open access: articles freely available online

- High visibility within the field

- Retaining the copyright to your article

Submit your next manuscript at $>$ springeropen.com 